\title{
Archivo camp. Memorias visuales e
} identidades outsider. 
CAMP FILE. VISUAL MEMORIES AND OUTSIDER IDENTITIES.

\section{ABSTRACT}

Since the last decade we can find references to camp in the culture and entertainment industries. From Eduardo Casanova with his film Pieles and his personal Instagram account, including John Waters, the designer Palomo Spain, the success of the American series Pose or the theme of the MET Gala this year. Camp is in a stream of contemporary aesthetic sensibility that has to do with the remixing of archives and encyclopedias for the digital hypertext culture. This resurgence of camp is documented on Instagram, where thanks to the streaming power of the social network, the concepts of camp, kitsch, as well as the visual imaginaries outsider are still and becoming fashionable and penetrating the aesthetic practices of the millenials, allowing them to know and develop new identities and aesthetics that are reflected through the network again.

\section{Keywords}

Camp, Photography, Memory, Performativity, Millennials.

\section{RESUMEN}

Desde la segunda década del siglo XXI podemos encontrar referencias camp en diversos ámbitos de las industrias culturales y del espectáculo. Desde Eduardo Casanova con su película Pieles y su cuenta personal de Instagram, pasando por John Waters, el diseñador Palomo Spain, el éxito de la serie estadounidense Pose o la temática de la Gala MET de este año. Lo camp se ensambla en una corriente de sensibilidad estética contemporánea que tiene que ver con la remezcla de archivos y enciclopedias propia de la cultura digital hipertextual. Este resurgimiento de lo camp queda documentado en Instagram, donde gracias al poder difusor de la red social, se mantienen y expanden los conceptos de camp, kitsch, así como los imaginarios visuales outsider, poniéndose de moda y penetrando en las prácticas estéticas de los millennials, permitiéndoles conocer y desarrollar nuevas identidades y estéticas que quedan plasmadas de nuevo en la red.

\section{Palabras Clave}

Camp, Fotografía, Archivo, Performatividad, Millennials. 


\section{INTRODUCCIÓN}

En la siguiente investigación analizaremos desde una perspectiva sociosemiótica y comunicativa cómo se está recuperando lo camp mediante los nuevos procesos de archivos fotográficos digitales que se dan en las redes sociales.

Lo camp está hoy más presente que nunca y es gracias a las nuevas dinámicas de memoria digital con las que Ixs nativxs hemos crecido. Las redes sociales como archivos fotográficos fomentan la recuperación de estéticas y estilos de vida pasados y propagan formas de activismos identitarios.

Dentro de esta recuperación estética nos topamos con el gusto por lo camp que, como Susan Sontag definía en su primera nota, es "una cierta manera de esteticismo. Es una manera de mirar al mundo como fenómeno estético. Esta manera, la manera camp, no se establece en términos de belleza, sino de grado de artificio, de estilización" (Sontag, 2018, p.553). Uno de los ejemplos contemporáneos del retorno de ese esteticismo lo encontramos el pasado año con la celebración de la gala MET 2019 en honor a lo camp. Con esta puesta en escena en el mundo de la alta costura hallamos otra industria que ha sucumbido y celebrado lo camp de nuevo. Además de los medios de comunicación convencionales, Instagram ha servido más que ninguno como escaparate mundial de todas aquellas celebridades participantes en el evento.

Se trata, entonces, de un acercamiento de unas estéticas e identidades camp que las nuevas generaciones no tenían interiorizadas en su enciclopedia. La generación $Z$, conocida como millennials, se ha convertido en una fuente de prosumidorxs, demandantes y seguidorxs de la estética camp que no ha pasado desapercibida para las industrias culturales. La performatividad de la que Butler (2007) hablaba encuentra su culmen en la ejecución de la estética camp:

Como consecuencia de una performatividad sutil y políticamente impuesta, el género es un "acto", por así decirlo, que está abierto a divisiones, a la parodia y crítica de uno mismo o una misma y a las exhibiciones hiperbólicas de "lo natural" que, en su misma exageración, muestran su situación fundamentalmente fantasmática. (p.285)

Esta performance de la exageración, del surrealismo, provoca unas dinámicas en las redes sociales de autoexposición de unas identidades que proyectan Ixs millennials y que fomenta una corriente de feedback entre las industrias, las celebridades del entretenimiento y Ixs jóvenes. Lo camp se circunscribe dentro de los imaginarios visuales de las redes sociales como una respuesta a una sensibilidad outsider que cada vez se manifiesta de forma más evidente. La juventud parece encontrar en lo camp una estética a la que adherirse y que permite dar rienda suelta a nuevas formas de creatividad que conforman una suerte de activismo despolitizado; un activismo estético en tanto que visibiliza y celebra lo queer sin ningún tipo de alegato, más que la intención de romper con las ideas preconcebidas de forma desconcertante y lúdica.

La fotografía sirve como vehículo para la propagación de estos imaginarios no normativos, en aras de una democratización de la hegemonía visual, al tiempo que es un medio idóneo para comunicar la propia identidad con una libertad creativa ilimitada, otorgando al sujeto agencia para decidir cómo se quiere mostrar.

Al mismo tiempo, los archivos fotográficos y multimedia que se difunden por las redes sociales contribuyen a que los millennials encuentren referentes identitarios. En este sentido, lo camp se 
presenta como un referente fundamental para unas generaciones nacidas en la transición entre lo analógico y lo digital, alfabetizadas en la cultura del hipertexto. Jóvenes desencantadxs que encuentran sus referentes en estéticas disruptivas, re-mezcladas y queer, manifestándose en visualidades como el vaporwave (imaginería propia de las páginas web de finales del siglo XX) y el glitch (estética basada en errores digitales, ya sean intencionados o por accidente, como distorsiones, píxeles superpuestos o imágenes multiplicadas, entre otros ejemplos).

\section{2 ¿Qué es camp? Aproximaciones al concepto.}

Es el estilo lo que nos hace creer en algo, sólo el estilo. (Wilde, 2012, p.58)

Una aproximación histórica al término camp dataría de las ambigüedades de género en los estilos estéticos de las burguesías inglesa y francesa del siglo XVIII. Como término todavía hoy se encuentran ambigüedades en su definición, pero como hábito, como maneras, como comportamiento, puede comenzar a señalarse al estilo rococó de la corte francesa, caracterizado por el artificio y el exceso, y a los hombres afeminados de la aristocracia inglesa victoriana. Sontag (2018) afirma:

El punto de partida más preciso parece estar situado a finales del XVII y principios del XVIII, debido a la extraordinaria inclinación del período al artificio, la superficie, la simetría; su gusto por lo pintoresco y lo emocionante, sus elegantes convenciones para representar la emoción inmediata y la absoluta presencia de carácter: el epigrama y el pareado (en las palabras), lo florido (en el gesto y en la música). (p.357)

Cabe señalar que uno de los orígenes que se le concede al término camp proviene del concepto francés Se camper (Prono, 2008, p.53), que el diccionario Larousse define como: "Prendre une attitude assurée ou fière et provocante"1. . Es decir, adoptar una pose, una actitud provocativa. Si por algo se caracterizan las burguesías es por sus actitudes burlescas y altaneras hacia el resto la sociedad, y las aristocracias inglesas y francesas de época solían hacer unos retratos exagerados de lo vulgar en particular y de la feminidad en general. La opulencia de la corte francesa del siglo XVIII quedó plasmada en una vestimenta donde los peinados con pelucas exageradamente grandes, maquillaje tanto en hombres como en mujeres, exceso de adornos y complementos en el vestuario, hicieron de la extravagancia el objeto de deseo de la moda y un elemento especialmente llamativo en el vestuario masculino. Lo mismo ocurría con la burguesía inglesa, donde los dandis establecieron el juego de la ambigüedad sexual y la estética extremadamente cuidada y refinada en hombres.

Como puede verse en la definición francesa del término, en sus inicios se hace referencia más a una actitud, una pose, que a un estilo estético o una identidad. Es el placer del acto provocativo convertido en algo estético, como señala Jauss (1986):

Mientras en el placer elemental el yo se anula y el placer, mientras dura, se basta a sí mismo y no tiene relación con el resto de la vida, el placer estético necesita un momento más: el del acto de adoptar una postura, que deja de lado la existencia del objeto, convirtiéndolo así en objeto estético. (p.71)

Esto es importante señalarlo, sobre todo para entender la idea de camp en la cultura popular del siglo XX y su representación en las industrias culturales, porque el acto de posar o tener 
una pose va ligado al hecho de ser camp, especialmente en la cultura queer y los ballroom y porque, precisamente por pose (o posing en inglés), es por lo que empieza a señalarse y a identificarse la homosexualidad con el travestismo, el artificio y lo no normativo: "El concepto de una identidad de género original o primaria es objeto de parodia dentro de las prácticas culturales de las travestidas, el travestismo y la estilización sexual de las identidades butch/ femme" (Butler, 2007, p.268).

Pero, el epítome de lo camp en cuanto a cultura popular se refiere podemos encontrarlo tanto en la figura como en la obra de Oscar Wilde. Prono (2008) afirma:

Although Wilde did not use the word camp, one of his most famous epigrams from the play An Ideal Husband (1895) has come to embody the Victorian roots of the sensibility: "To be natural is such a very difficult pose to keep up." Being natural is here defined as a pose in itself and thus loses its more obvious meaning to be connected, instead, to aestheticism with which camp is also linked. (p.53)²

A lo largo de los textos del escritor irlandés podemos observar en las descripciones de sus personajes un cierto comportamiento afeminado en sus protagonistas masculinos. Un amaneramiento que, en la época, podía pasar para unos como buenas maneras propias de la burguesía anglosajona pero que, para otros, eran signo de homosexualidad, sodomía, y motivo de castigo. Una ambigüedad en el género y la sexualidad que, como indica Butler, aún ocurre: “Los géneros diferenciados son una parte de lo que 'humaniza' a los individuos dentro de la cultura actual; en realidad, sancionamos constantemente a quienes no representan bien su género" (Butler, 2007, p.272).

Su refinamiento, su sentido del humor mordaz y sarcástico, la sensibilidad de su narración y la forma en la que los temas son tratados en su obra indicaban una fascinación de Wilde por lo exagerado, por la feminidad y por la ostentación que marcaban el camino de una primera idea de lo camp. Precisamente por su manera camp fue por lo que fue acusado de sodomía por el marqués de Queensberry (Woods, 2019) en 1895. La incriminación por sodomía, delito castigado con la cárcel, la realizó el marqués de Queensberry mediante una nota en la que se podía leer "For Oscar Wilde, posing somdomite" (Frankel, 2017, p.31) acusando a Oscar Wilde de sodomita. Pero, no es tanto la acusación de su homosexualidad como el hecho de que "pose" (posing), de que actúe como tal lo que desencadena una serie de juicios entre Wilde y Queensberry por difamaciones y acusaciones de sodomía y comportamiento indebido que terminan por llevar al escritor a la cárcel.

Una vez iniciado el siglo XX, instituciones culturales y lingüísticas anglosajonas intentaron definir el concepto camp con referencias a la homosexualidad masculina, convirtiéndolo en un término más del argot utilizado por hombres gays (Macdonald, 2017). Pero, a pesar de todos esos acercamientos e intentos de definir la idea de camp, no es hasta el ensayo de Susan Sontag en 1964, Notas sobre lo Camp, cuando empieza a asentarse teórica y académicamente la palabra camp ya no sólo como pose o comportamiento sino como estilo e identidad: "Lo camp es una concepción del mundo en términos de estilo; pero de un tipo particular de estilo. Es el amor a lo exagerado, lo off, el ser impropio de las cosas." (Sontag, 2018, p. 355). Poco después, con los disturbios de Stonewall en 1969, se empiezan a visibilizar otras identidades no-normativas, el colectivo LGBTIQ+ aparece como algo fuera de la norma, algo que siempre ha existido, pero ha sido considerado como una otredad, algo raro y enfermizo, como se había definido con anterioridad lo camp. Es entonces cuando lo camp y lo queer se relacionan como identidades 
fuera de la heteronorma, ponen en cuestión lo establecido y aceptado hegemónicamente. Ya no es algo perverso ni exclusivo de la homosexualidad masculina, sino que abarca a un mayor número de cuerpos, identidades y performatividades, como constatan los trabajos de Esther Newton y Judith Halberstam.

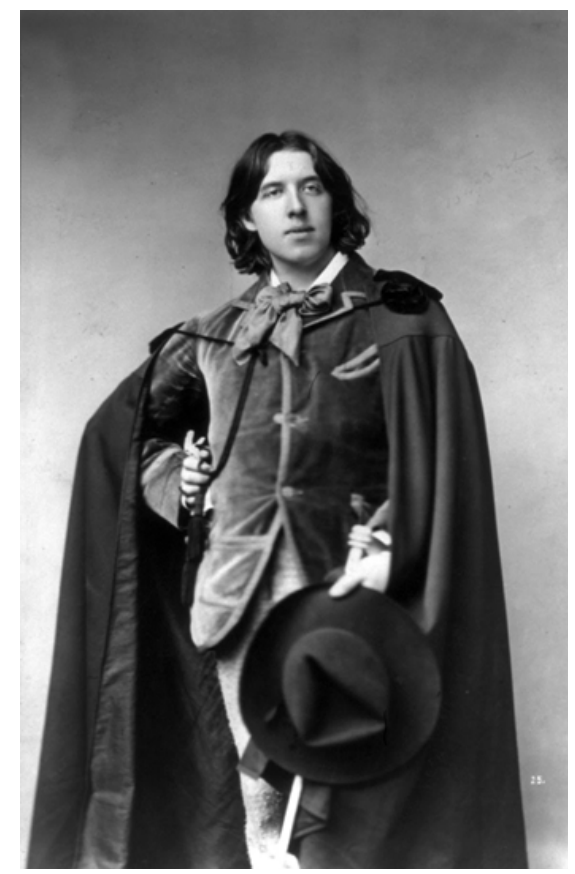

Figura 1. Oscar Wilde, circa 1882.

https://www.gettyimages.es/fotos/oscar-wilde?mediatype=photography\&phrase=oscar\%20wilde\&sort=mostpopular

Newton, en su investigación Mother Camp. Un estudio de los transformistas en los Estados Unidos (2016), pone de manifiesto a través de entrevistas a transformistas y drag queens la influencia que han tenido en el colectivo estrellas de cine como Marlene Dietrich a la hora de configurar su estilo, cómo construyen esas identidades no normativas y cómo confluye todo ello en sus performance entre una feminidad exagerada, camp, y su identidad masculina: "De este modo, cuando los artistas están actuando, el enfrentamiento se produce entre la 'apariencia', que es femenina, y la 'realidad' o la 'esencia', que es masculina." (p.143). Por otra parte, el estudio de Halberstam, Masculinidad femenina (2008), profundiza en las diferentes masculinidades y la subcultura drag king analizando las performances y los procesos de transformación: "Cuando las performances de los drags kings son camp, ello es generalmente porque la actriz permite que su feminidad afecte e influya en la masculinidad que está interpretando." (p.265). Por lo tanto, en palabras de Silvia Hueso Fibla (2009): "tanto lo camp como lo queer serán modos de posicionarse contra el orden dominante por parte de miembros que no pertenecen a él; evidenciarán la no-unicidad del sujeto y la desviación de la norma hegemónica" (p.6). 


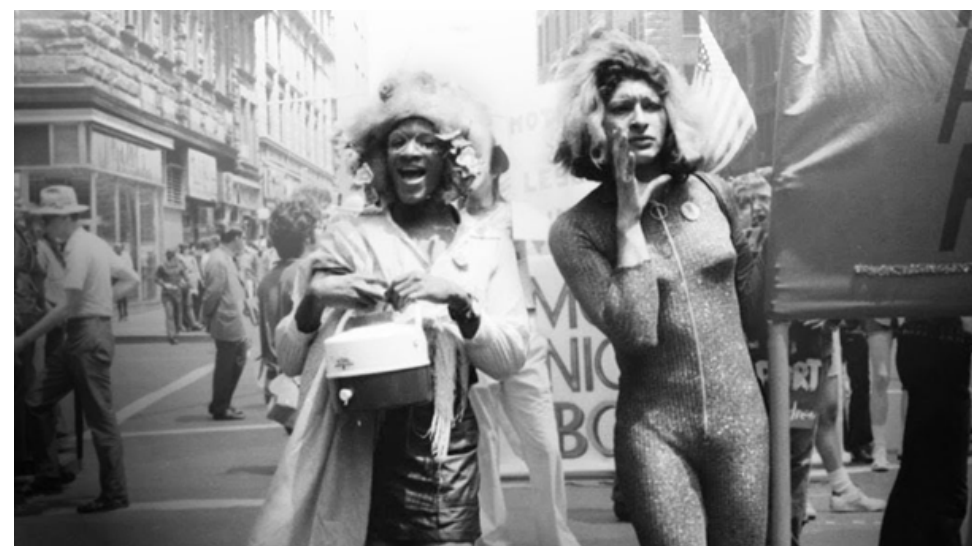

Figura 2. Las activistas Marsha P.Jonshon y Sylvia Rivera durante una manifestación por los derechos del colectivo LGTB en 1969.

https://aldianews.com/sites/default/files/articles/sylvia.jpg

Paralelamente a la divulgación del término camp por Sontag entre las esferas académicas y culturales, y a la visibilización y notoriedad que consigue el colectivo LGBTIQ+ gracias a Stonewall, la aparición de la televisión provoca que la sociedad de consumo normalice lo camp a través de productos provenientes de las industrias culturales. Como señalaban Theodor Adorno y Max Horkheimer (2007): "El mundo entero es conducido a través del filtro de la industria cultural." (p.171), y es, mediante esas industrias culturales como el cine y la televisión, por donde se filtraba al público de masas personajes, identidades y referentes camp. Todo lo fantástico, lo extraordinario, lo raro, lo obsceno, lo creepy, surgía como productos culturales y se asentaban como los inicios de la cultura pop. Estos referentes camp consiguieron (y consiguen) admiración, fans, personas que se identifican con esa extrañeza y convierten lo camp en algo de culto, en una reivindicación festiva de lo distinto. Como veremos a continuación, hoy en día esto sigue sucediendo con la producción de anuncios de gominolas con una estética retro que los convierte en pequeños cortos camp, o eventos mundialmente conocidos como la Gala MET de moda y costura, cuya temática ha sido dedicada a lo camp.

\subsection{Lo camp en las industrias culturales}

Camp's connection with Hollywood has manifested itself in two main ways: through the work of queer artists within the mainstream entertainment industry, and through the trans-semiotic re-readings of Hollywood narratives, specifically star images, that queer audiences have engaged with for the purpose of altering the social perception of queerness. (Austin, Qiong Yu y Malinowska, 2017, p.190)³

El 6 de mayo de 2019 tuvo lugar la celebración de una de las galas más importantes de la industria de la moda: la Gala del MET. Como cada año desde hace 71 años, el Museo Metropolitano de Arte de Nueva York acoge la gala de su Costume Institute donde no sólo artistas, diseñadoras y diseñadores, modelos y demás profesionales de la moda se dan cita, sino que demás celebridades de la industria cultural y del entretenimiento asisten al evento benéfico. Cada año, 
la gala tiene un tema protagonista de la exhibición y en el que las y los invitados basan sus trajes para dicho evento. Este año, el tema en el que se inspiraba la gala fue lo camp, con el título Camp: Notes on Fashion haciendo alusión al ensayo Notes on Camp (1964) de Sontag.

Andrew Bolton (Bowles, 2019), el comisario del Institute, declaró en la revista Vogue cómo cada vez más lo camp está calando en todos los ámbitos de la sociedad: "(Camp) become increasingly more mainstream in its pluralities - political camp, queer camp, pop camp, the conflation of high and low, the idea that there is no such thing as originality"4, destacando también, esta vez en una entrevista al periódico The New York Times (Friedman, 2018), la importancia de la influencia de una cultura camp entre lo considerado marginal o discriminado: "we are going through an extreme camp moment, and it felt very relevant to the cultural conversation to look at what is often dismissed as empty frivolity but can be actually a very sophisticated and powerful political tool, especially for marginalised cultures." ${ }^{5}$

Citando a diseñadores de la talla de Saint Laurent y Marc Jacobs como influencias camp en la moda Bolton indicaba así la magnitud del estilo camp en el mundo creativo. Además, la exhibición se dividió en dos partes: la primera exploraba los orígenes camp, desde la época victoriana hasta los disturbios de Stonewall de 1969, pasando por el uso que se le da a la palabra camp entre la comunidad queer; y la segunda parte se centró en las interpretaciones artísticas que diseñadores contemporáneos como Balenciaga y Prada habían hecho de lo camp. Porque, como define Luca Prono (2008): "Camp is not only applicable to artistic expressions that are made by queers for the consumption of a queer audience, but it extends to mainstream texts whose images, ideologies, and readings qualify them as being about heterosexuality" (p.52). ${ }^{6}$

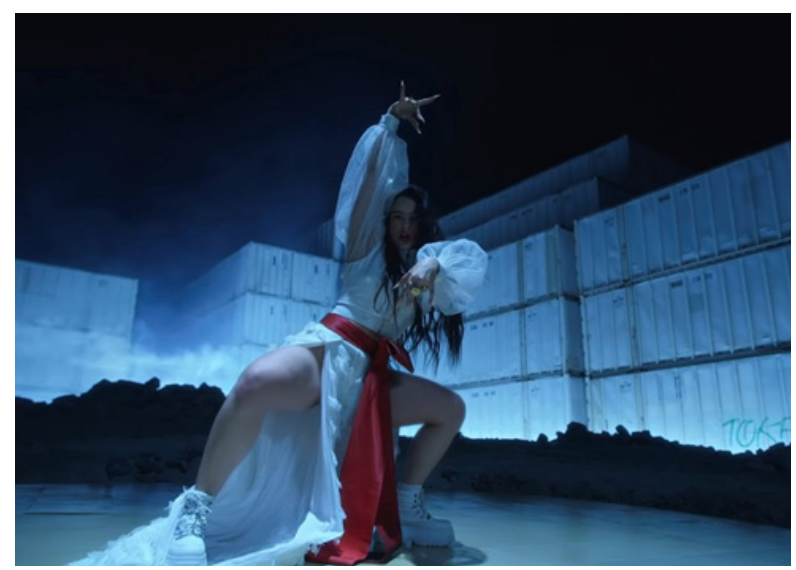

Figura 3. Rosalía, con vestuario de Palomo Spain, en su videoclip "A palé". https://www.youtube.com/watch?v=5zwpwbdGNIk

En España encontramos a dos jóvenes creadores como principales exponentes de lo camp en las industrias culturales, ambos millennials y ambos usuarios de las redes sociales. El primero es el diseñador de moda Alejandro Gómez Palomo, más conocido por su marca, Palomo Spain. "El camp es necesario. Por suerte, creo que estamos volviendo a ese momento en el que todos podemos ser más camp, extravagantes y extraordinarios" fue lo que el diseñador afirmó en la 
revista Vogue (Gómez Urzaiz, 2019) cuando le preguntaron por su participación en la MET Gala 2019. Entre las celebridades e iconos de las generaciones $Y$ y $Z$ a las que ha vestido encontramos a la cantante Rosalía, Madonna, Beyoncé o la actriz Úrsula Corberó para el videoclip del cantante C. Tangana, el cual fue dirigido por Eduardo Casanova, siguiente ejemplo de industria camp.

Eduardo Casanova se ha consagrado en los últimos años como un director camp, un realizador kitsch en la línea de cineastas como John Waters y los hermanos Mike y George Kuchar. Con su corto Eat my shit (2015) y posterior película Pieles (2017), ensalza la estética camp al mainstream acercándola así a toda una generación no acostumbrada a ella. En sus obras recurre a Ixs consideradxs freaks, a la colorimetría brillante e impactante, a lo hortera, al estilo "rosa chicle" del universo Barbie, al artificio para proyectar lo que para unas personas es lo malo, la fealdad, lo obsceno, lo estándar, como indica Thorsten Botz-Bornstein, "Camp is very much based on this ironical attitude toward kitsch, as are "postmodern" ways of using kitsch motives attempting to challenge official aesthetic standards." (Botz-Bornstein, 2019, p.90)7. Sus últimos trabajos, el ensayo fotográfico Márgenes: un ensayo artístico sobre el ser humano y la estética, en el que como él mismo dice: "El libro hace una reflexión sobre el kitsch, que es, como el camp, la estética que parodia lo que está dentro del sistema, la que se encarga de reírse de todo y que a la vez es discriminada porque alaba lo feo." (Simón, 2019). Y los nuevos anuncios publicitarios que ha dirigido para la marca de gominolas Vidal muestran un ejercicio estético donde el lumpen se junta con elementos camp y kitsch, todo lo que está al margen de lo normativo y del estilo estético predominante, y que manifiestan una nueva ola de lo camp en la cultura millennial y postmillennial.

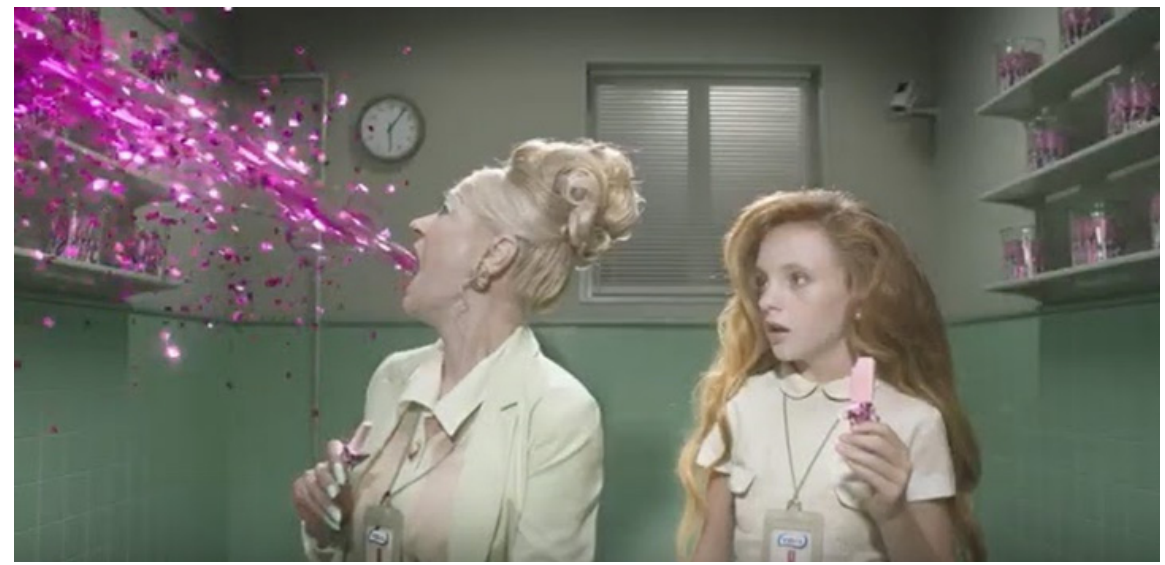

Figura 4. Escena del anuncio "Dipper Pad" dirigido por Eduardo Casanova para Vidal Golosinas. https://www.youtube.com/watch?v=1mS2EZ5mDBc

Estamos viviendo, pues, una reivindicación camp por parte de dos generaciones jóvenes que lo están resignificando y adaptando a sus percepciones de estilo y a sus herramientas estéticas y comunicativas: "Dichos actos, gestos y realizaciones - por lo general interpretados - son performativos en el sentido de que la esencia o la identidad que pretenden afirmar son invenciones fabricadas y preservadas mediante signos corpóreos y otros medios discursivos" 
(Butler, 2007, p.266).

Las industrias culturales están elevando productos, estilos, artistas y personajes que representan lo camp ante millennials y postmillennials, enseñándoles que hay una corriente que combina la alta cultura con la baja cultura, la cultura pop expresada como pastiche, con artificio y teatralidad, en exceso y exageración, que mezcla lo mainstream con la nostalgia y sin abandonar la ironía intrínseca del camp. Lo que provoca una repetición de esa estética. Estamos ante algo que ya predijeron Adorno y Horckheimer: "Pero lo nuevo está en que los elementos irreconciliables de la cultura, arte y diversión, son reducidos, mediante su subordinación al fin, a un único falso denominador: a la totalidad de la industria cultural. Esta consiste en repetición." (Adorno y Horkheimer, 2007, p.180).

\subsection{Generación $\mathrm{Y} / \mathrm{Z}$}

La curiosidad estética (más que el puro placer por mirar o el mirar con la boca abierta algo nuevo) puede ser considerada ya como una nueva forma de ver que tiene, además, una función descubridora. (Jauss, 1986, p.32)

Alvin Toffler (1991), acuñó el término prosumidxr (prosumer) para definir a aquellas personas que, mediante un ejercicio de retroalimentación, consumían productos culturales y a la vez producían otros contenidos culturales. Años después, Axel Burns (2009) nombra produsuarixs (produser) a individuxs que ejercen otra práctica de retroalimentación, pero, esta vez, en forma de producción colaborativa y abierta de información. Las generaciones $Y$ y Z , millennials y postmillennials, son aquellas que han crecido y nacido en un mundo totalmente digitalizado: "crean sus identidades según lo que ven en las redes las cuales son las principales fuentes de información en cuanto a tendencias y noticias que utilizan las nuevas generaciones." (Marinas, 2019, p.188). Estxs nativxs digitales se desenvuelven con y entre las tecnologías con una facilidad que generaciones anteriores no son capaces ni de imitar ni de entender. Lo mismo sucede con las identidades queer y camp tan integradas y celebradas entre millennials y postmillennials y tan poco reconocidas por gran parte de generaciones predecesoras las cuales, en ocasiones, se muestran escépticas ante tales identidades. Queer tal y como hoy lo conocemos surge a modo de resignificación y reapropiación del término anglosajón Queer que, como explica Javier Sáez: "[...] en inglés es el insulto homófobo por antonomasia: es maricón, bollera, rarito, es todo aquello que se sale de lo normal y pone en cuestión lo establecido." (Platero, Rosón y Ortega, 2017, p.381).

Y es, precisamente, en estas dos generaciones donde prosumidorxs y produsuarixs conectan y se reproducen en las redes sociales, especialmente en Instagram. Y es ahí, en Instagram, donde se consumen, se producen, se reproducen y se difunden nuevas (y viejas) identidades, como la identidad camp: "These performers have remade camp for a postqueer, new media world." (Christian, 2010, p.370). ${ }^{8}$ Las generaciones Y y Z utilizan Instagram como archivo para documentar y mostrar sus looks, los locales que frecuentan, quién les fotografía (si es que recurren a fotógrafxs), qué marcas utilizan, dónde compran su ropa, etc. Toda esta información la publican en un solo post, en una foto o video (o ambos), y con ella expanden una idea de identidad, una forma de ser y estar, la performatividad de un estilo concreto. Nos encontramos, pues, ante un par de generaciones que viven las identidades queer y camp y las exponen a través de las redes sociales tanto a followers, como a curiosxs, a indiferentes, como a gente que 
va a repudiarles: "the screen and the computer create multiple identities, creating a fragmented experience." (Christian, 2010, p.354)..$^{9}$ Y lo hacen siendo a la vez prosumidorxs y produsuarixs. Como hemos visto antes, las identidades queer y camp han formado parte de la cultura pop y las industrias culturales desde hace décadas. Con mayor o menor repercusión, según el contexto y el momento, pero han sido influenciadas e influyentes:

La identificación estética se realiza en un movimiento de vaivén entre el observador, estéticamente liberado, y su objeto irreal. Ello sucede cuando el sujeto que disfruta estéticamente adopta toda una escala de posturas e introduce, en su mundo personal, la propuesta de un modelo, aunque también puede dejarse llevar por la fascinación del simple placer de mirar, o caer en una imitación involuntaria. (Jauss, 1986, p.161)
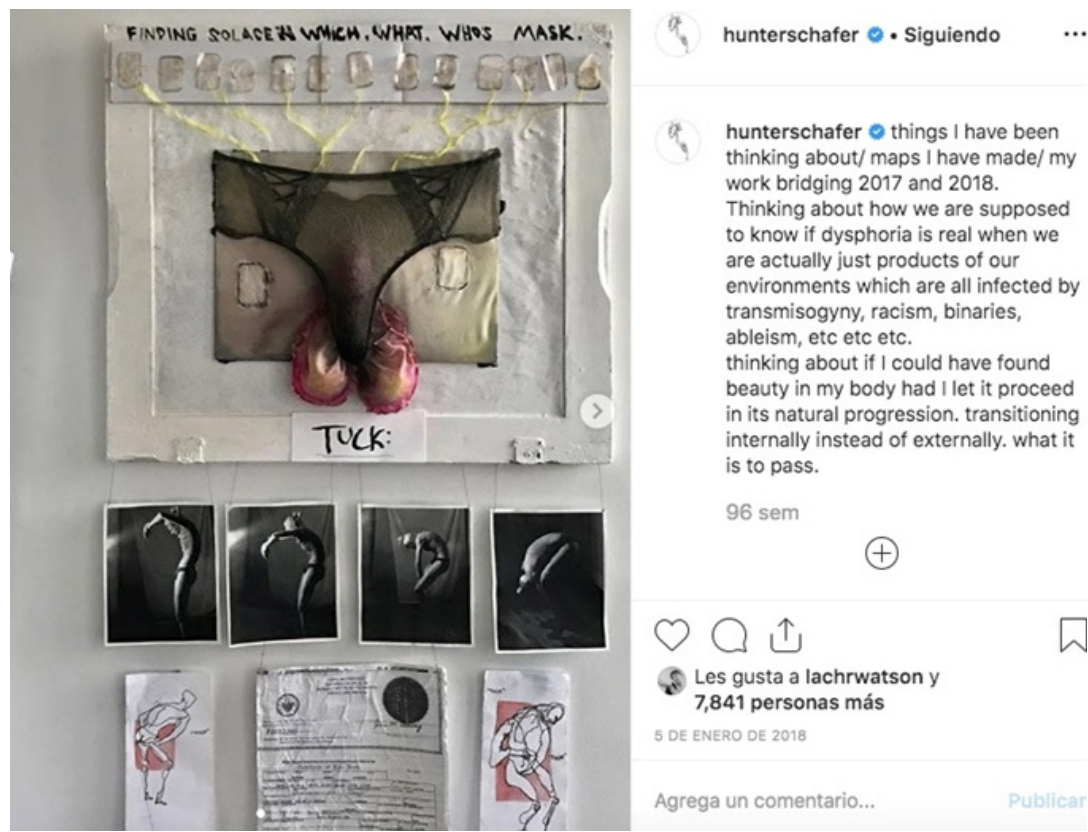

is to pass.

96 sem

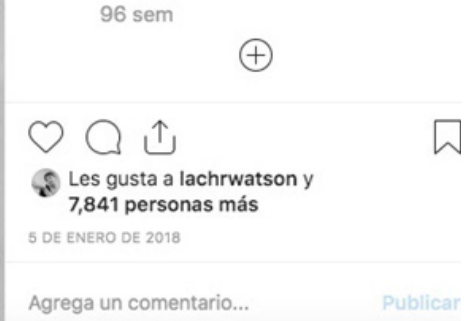

Figura 5. Imagen de la cuenta de Instagram de Hunter Schafer. https://www.instagram.com/hunterschafer/

Lxs millennials y postmillennials actúan como prosumidorxs cuando consumen productos como la serie POSE, publican su visualización o una captura de la mencionada serie y, además, comentan cómo o si se identifican con sus personajes y tramas, ya sea por identidad queer o camp. Con ello, se generan (nuevos) contenidos culturales concretos para un sector específico de contenidos culturales que han sido lanzados para un sector generalista, mainstream. $\mathrm{O}$ actúan como el ya mencionado Eduardo Casanova o el actor no binario Lachlan Watson, Ixs cuales consumen, producen y comparten su identidad, su obra y sus conocimientos sobre, en este caso, lo camp, lo kitsch e identidades queer. Es entonces cuando las identidades prosumidora, produsuaria, queer y camp acaban fusionándose y proyectándose por igual en la red social Instagram: Ixs usuarixs de Instagram son a la vez prosumidorxs y produsuarixs debido a los 
usos que le dan a sus cuentas y, en el caso concreto de personas queer y fans camp, sus post proyectan su identidad queer con una estética camp lograda ya sea por sus looks y vestimentas y poses o gracias a los filtros que Instagram y los smartphones/IPhones proporcionan para lograr el artificio en la fotografía.

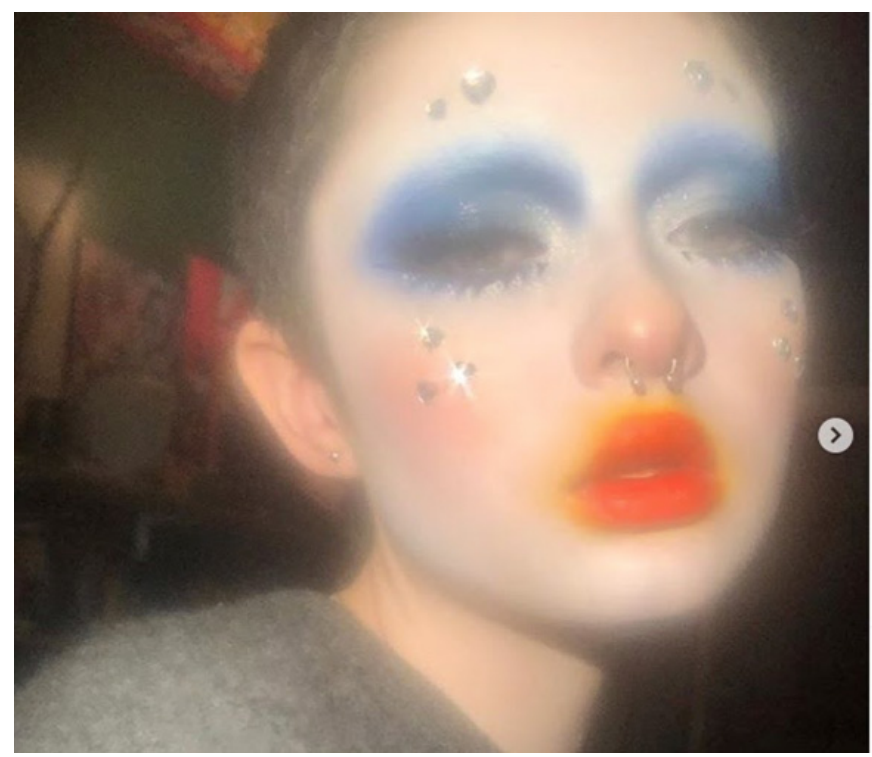

lachrwatson $\bullet \cdot$ Siguiendo

lachrwatson $\bullet$ thank u @imp_kid for being so damn inspirational

42 sem

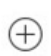

abrahamgalvez96 Applause -

Lady Gaga

27 sem 5 Me gusta Responder

jadexscissoring SNAPPED

26 sem Responder

liplickedashes loveee

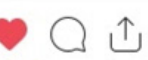

(.) Les gusta a imp_kid y

52,397 personas más

Figura 6. Imagen de la cuenta de Instagram de Lachlan Watson. https://www.instagram.com/lachrwatson/

El trabajo de identificación y reconocimiento por parte de Ixs usuarixs hacia el trabajo y la fotografía que están viendo en Instagram, es lo que logra que se creen y se expandan ciertas modas e identidades. Lo camp, el gusto por la teatralidad y lo exagerado, también puede verse en diversas cuentas de Instagram, sobre todo de celebridades queer que celebran cada vez más la estética camp y publican abiertamente la identidad con la que se identifican. Christian (2010) añade:

Yet camp online is too personal and singularly important for many younger performers to detach. This generational divide between the more traditional camp performers and the younger, Web 2.0-minded ones who are more personally invested has its roots in history. (p.369)10

\subsection{Apropiación camp en la era de las redes sociales}

The Youtube videos (...) suggested a historically specific shift in young people's relationship to new media, camp, and queer history, marking the move from marginal, ironic, community-forming camp to more mainstream, earnest, personally inflected forms online. (Christian, 2010, p.357) ${ }^{11}$ 
La apropiación y re-significación de lenguajes, estéticas e imágenes es una práctica que se lleva dando desde el siglo XX y sin la cual no se puede entender la cultura contemporánea. Michel de Certeau en su libro La Invención de lo cotidiano, analizó en la década de 1980, las prácticas de la vida cotidiana de los individuos y cómo la industria penetraba en lo ordinario, a través de la cultura y los medios de comunicación. En su análisis, hacía distinción entre las "estrategias" que la industria y las estructuras de poder imponían a través de sus productos (culturales y de consumo) y las "tácticas" que Ixs usuarixs desarrollaban al tomar estos productos, y re-significar sus usos, dando lugar a una apropiación imprevisible por parte del usuario. Desde luego, la situación ha cambiado mucho tras la digitalización y el advenimiento de internet y el software libre. La tendencia a la personalización y customización del consumo es un hecho al que la industria ha sabido adaptarse. Y la cultura del do it yourself se celebra enormemente también por la industria, que ha desarrollado de nuevo, estrategias que proporcionan al consumidor aquello que necesita. Es importante comprobar cómo las situaciones que describe de Certeau no han cambiado tanto en esencia, como su concepto de escamoteo, el cual encontramos aplicable al sistema actual de ocio y trabajo que producen las redes sociales: "[...] no es sino un caso particular entre todas las prácticas que introducen jugarretas de artistas y competencias de cómplices en el sistema de la reproducción y del compartimento mediante el trabajo o el tiempo libre." (de Certeau, 2000, p.35). Lo que viene a apuntar que la cultura generada por la industria y la que genera el usuarix se encuentra siempre en continua conversación y tensión, conformando un juego de apropiaciones y re-apropiaciones que es difícil señalar dónde empieza y dónde acaba.

La era de las redes sociales ha puesto como protagonista al usuarix, quien selecciona y crea su propio contenido. Estas nuevas dinámicas de búsqueda, selección y creación de datos e información no se quedan enmarcados solamente en el ámbito cultural y de ocio, sino que se han extrapolado a todos los modos en los que conseguimos, y proporcionamos, conocimiento. Como indican Suárez Villegas y Cruz Álvarez (2015), en los últimos años ha habido un aumento del recurso de las redes sociales como fuentes de información y difusión de contenido, sobre todo entre las personas más jóvenes, principales usuarixs y produsuarixs de estas plataformas. El impacto de las redes sociales como Instagram, Twitter, Facebook y YouTube es tal que incluso los medios de comunicación convencionales han tenido que adaptarse actualizando la forma en la que difunden contenidos y apropiándose de nuevos conceptos digitales hasta ahora alejados, e incluso desconocidos, de toda una generación anterior de personas que sólo obtenían información mediante el telediario y la prensa:

El resto de usuarios que sí consumen información ensalzan las redes sociales como el medio de comunicación del siglo XXI, al ofrecer la posibilidad, de forma gratuita, de conocer los intereses de la sociedad y las últimas tendencias, imponiéndose cada uno su propia agenda informativa. (Suárez y Cruz, 2015, p.626)

Esta cultura del creador de contenido tiene un gran impacto a la hora de difundir imaginarios no normativos y, por tanto, contribuir a la conformación de identidades alternativas. En la era postinternet, al produsuarix lo define, además de una práctica activa y colaborativa de generación de contenido, una percepción y gramáticas que ha adquirido como consecuencia de los hábitos de conectividad total en los que nos hallamos.

Las imágenes que se producen bajo estos hábitos tienen un cariz auto-consciente, en el sentido de que son el resultado de "la compulsiva acción de navegar y descargar" (Martín Prada, 
2017, p.46), como refiere la artista Marisa Olson, quien fue una de las pioneras en acuñar el concepto de post-Internet en el contexto del arte. Las imágenes que se producen y circulan en este contexto de omnipresencia de Internet y las redes sociales son, por tanto, imágenes que muestran esta nueva forma de vida y de pensamiento hipertextual, cuyo referente tan volátil como cualquier publicación de Instagram o YouTube, y que encuentra en el meme como tipología de imagen uno de sus ejemplos más claros: "While memes are seemingly trivial and mundane artifacts, they actually reflect deep social and cultural structures." (Shifman, 2014, p.15). ${ }^{12}$

Esta nueva conciencia post-Internet no emerge en un espacio y tiempo concreto, sino que es la consecuencia orgánica de la experiencia contemporánea, que tiene como referencia "el desarrollo de las economías de la atención, la mutabilidad y reproductibilidad infinita de los materiales digitales, la disolución de las barreras entre los espacios físicos y digitales" (Martín Prada, 2017, p.48). Esta conciencia atraviesa las estructuras del sentir del presente, un concepto que acuña Raymond Williams (1977) en su ensayo Marxismo y literatura, poniendo la dimensión sensible de la vida en valor para definir, por decirlo de alguna manera, la "sensibilidad de la época". Definir las estructuras del sentir resulta tan inasible como definir lo camp. Porque para entenderlo, hay que alinearse con ellas en la contemporaneidad. La experiencia en el ámbito digital tiene que ver mucho con la sensibilidad camp. Una experiencia en el que la idea de performatividad, la comunicación desde el yo y la lógica do it yourself tienen mucho protagonismo.

Lo camp resurge en las redes sociales como una respuesta a esta sensibilidad latente proponiendo las visualidades y economías afectivas (Ahmed, 2015) que las nuevas generaciones demandan. Y aparece en un espacio y tiempo en el que las lógicas post-Internet facilitan el desarrollo del discurso. La estética camp, al igual que el meme (como máximo ejemplo de la cultura visual de post-internet), son imágenes resultado de una cultura hipertextual. Tienen conciencia propia y hay que estar alfabetizadx en ellas para entenderlas. Ambas sensibilidades están basadas en un equilibrio entre lo lúdico y lo crítico. Son imágenes que reproducen, como diría Sontag (2018), una seriedad que falla. Lo camp y el meme adoptan una estética en ocasiones precaria, naif o kistch como marca de la tensión entre alta y baja cultura. Además, detrás de estas estéticas hay dinámicas colaborativas y autogestionadas (do it yourself).

\subsection{Instagram y los filtros faciales}

La información instantánea, convertida en un entorno, tiene el efecto de impulsar todos los efectos subliminales a la consciencia. Es decir, impulsa a la consciencia todas las formas excepto la suya propia, dado que el efecto del entorno electrónico está siendo el de volver a la gente hacia sí mismos y substituir el viaje interior por la exploración exterior, el ser por el llegar a ser. (McLuhan y McLuhan, 2009, p.17)

En los últimos meses hemos asistido al triunfo de una nueva poética de la conectividad: los filtros faciales, resultado de la remediación (Bolter y Grusin, 2011) del selfie, la Realidad Aumentada y la máscara. Si bien los filtros faciales existían desde 2011 en la plataforma Snapchat, es en instagram donde se ve potenciado su uso cuando los usuarios empiezan a tomar un papel activo en cuanto a la representación. En agosto de 2019 Facebook libera el software Spark AR, una tecnología basada en WYSIWYG (what you see is what you get), que permite a los usuarios 
diseñar sus propios filtros faciales gracias a una interfaz accesible e intuitiva.

Como resultado, los usuarios se lanzan a crear imágenes -muchas de ellas con una clara sensibilidad camp- y la red comienza a llenarse de posibilidades que desafían la visualidad hegemónica de los filtros que proponía la plataforma (como las populares filtros Bulldog, o Smooth Skin por ejemplo), que no solamente son naif e infantilizan, sino que también reproducen los cánones hegemónicos de belleza normativa femenina, considerando que afinan la cara, agrandan los ojos, ponen rubor en las mejillas y la piel lisa (ver Fig. 7 y 8). Se forman así comunidades conectadas de forma global a través de Internet, concretamente de la red social Instagram, unidas por la creación de identidades virtuales, unas identidades completamente outsiders, fuera de la norma, y que únicamente necesitan unos filtros digitales que o bien les son proporcionados por la aplicación o bien ellxs mismxs pueden crear:

Estas comunidades son importantes en buena medida por su capacidad de alcanzar audiencias globales y penetrar en los universos simbólicos de los individuos de una forma que la comunicación, a escalas grupales y masivas no consigue. Las narrativas autobiográficas potencian la sensación humanidad, a pesar de que el entorno online haga que las interacciones puedan parecer a priori un tanto desencarnadas. Sin embargo, es esta sensación de humanismo lo que crea un efecto de empatía que permite la apertura de espacios de resistencia respecto a la normatividad. (Jiménez, 2019, p.183)

La repercusión mediática que ha tenido la utilización de estos filtros digitales, de estas formas de identidades volátiles, ha captado la atención de otros medios de comunicación, como el periódico La Razón que llega a recomendarlos:

Si eres de las que te gusta tener buena cara, como las que lucen las famosas en sus redes sociales a primera hora de la mañana, entonces sigue leyendo porque este tema te interesa: tenemos su truco. Se trata de utilizar uno de los novedosos filtros de Instagram que además de tapar tus imperfecciones y posible cara de cansancio, te dibuja unas coquetas pecas que te animarán el aspecto. (Benito, 2019)

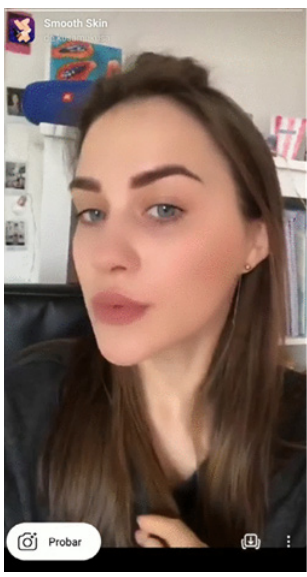

Figura 7. Captura de pantalla del filtro Smooth Skin. Instagram.com/kusamukusa.

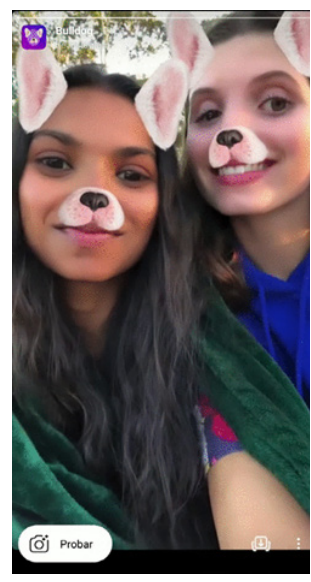

Figura 8. Captura de pantalla del filtro Bulldog. Instagram.com 
Esta tecnología de acceso libre es una herramienta que convoca a diversxs usuarixs y creadorxs que ven en el medio una forma de expresión identitaria, creándose una estética que redunda una y otra vez en el gusto camp. Esta redundancia en lo camp también puede ser considerada una práctica de reapropiación de esta estética puesto que, a pesar de mostrarse como una novedad, no lo es. Es, como indican Austin y Malinowska (2017):

It responds to the manufacture of mage and production of desire, attributed to the making of screen fantasy and, as such, becomes a platform for practices that exploit both stars "on-screen performances" and the "meanings about human identity" they represent. $(\text { p.188) })^{13}$

Por lo tanto, lo que sí es novedoso es el medio en el que esta nueva idea camp es proyectada. Como ya ocurría años atrás con la construcción de identidades camp a través de los medios novedosos de la época como podían ser el cine y la televisión, ahora estas identidades tan ficticias, pero a la vez tan reales las creamos y nos llegan mediante aplicaciones móviles. Como resultado de estas prácticas, aparecen filtros que re-significan y de-construyen las estéticas hegemónicas que anteriormente encontrábamos. Por consiguiente, no se puede pasar por alto que los filtros faciales han abierto nuevas posibilidades de marketing en las redes sociales muy llamativas para las compañías especializadas en maquillaje. Por ejemplo, el caso del filtro Lunaison, diseñado nada menos que por la compañía Gucci Beauty (ver Fig. 9).

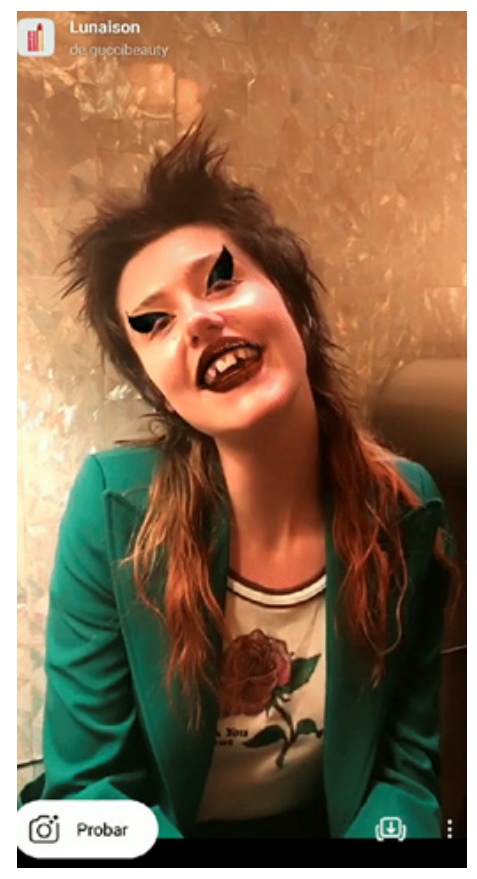

Figura 9. Captura de pantalla del filtro Lunaison. Instagram.com/guccibeauty

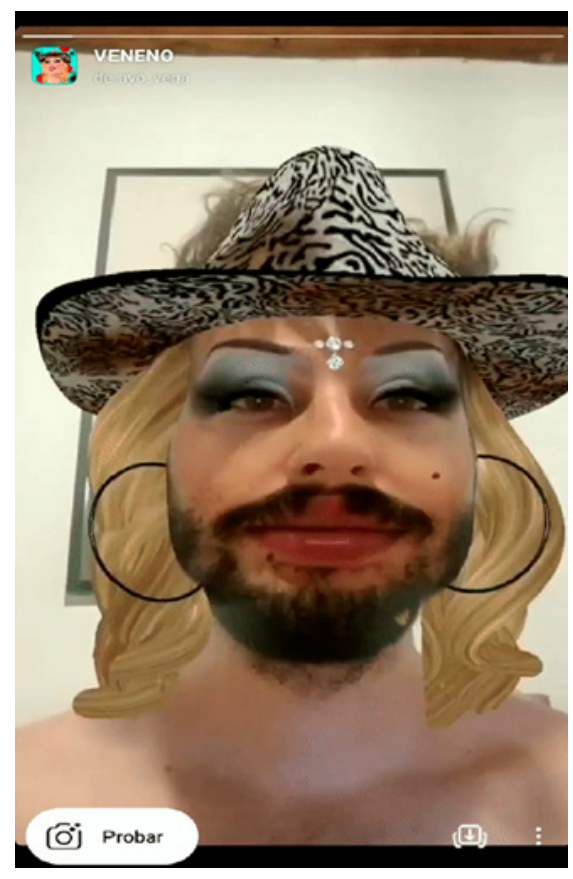

Figura 10. Captura de pantalla del filtro VENENO. Instagram.com/ayo_vega 
La realidad virtual aplicada a través de los filtros faciales se presenta como un nuevo escenario a través de los cuales Ixs usuarixs se pueden proyectar, ampliando las posibilidades de la performance online. Esta performance inmaterial es una fuente inagotable de revisiones a nociones como la de género y performatividad que usuarixs como @ayo_vega (ver Fig. 10) exploran en sus filtros, sin dejar de lado la dimensión lúdica y las referencias a la cultura pop.

Los filtros, en definitiva, sirven para revisitar muchas de las nociones que están en el imaginario milennial contemporáneo. Un caso muy destacado es el del creador Filip Custic (ver Fig. 11), creador milenial que saltó a la fama por diseñar la portada del disco El mal querer de Rosalía y promotor del estilo objetivista en la red que el autor describe como un mood creativo:

Me di cuenta de que los objetos significan algo personal para cada uno. Cogí este recurso creativo y lo llevé a mi terreno para construir mi vocabulario de objetos. En vez de cantar un tema, creo una pieza en la que los objetos cuentan una historia. (Del Barrio, 2019)

Usuarixs como @chrispelk (ver Fig. 13) con su filtro Spider Eyes propone una estética del extrañamiento similar a la que Ezra Miller lució en la gala del Met 2019 (ver Fig. 14)

El propio universo de la inteligencia artificial es revisado por usuarixs como @exitsimulation con su filtro Beauty_GAN (ver Fig. 15), que simula a una máquina extractora de datos biométricos del rostro.

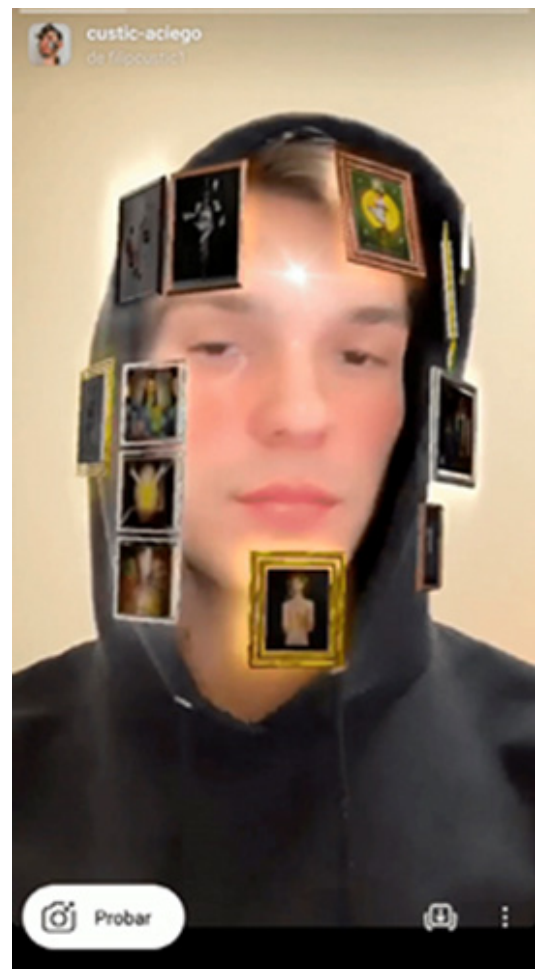

Figura 11. Captura de pantalla del filtro custic-aciego de @filipcustic1 


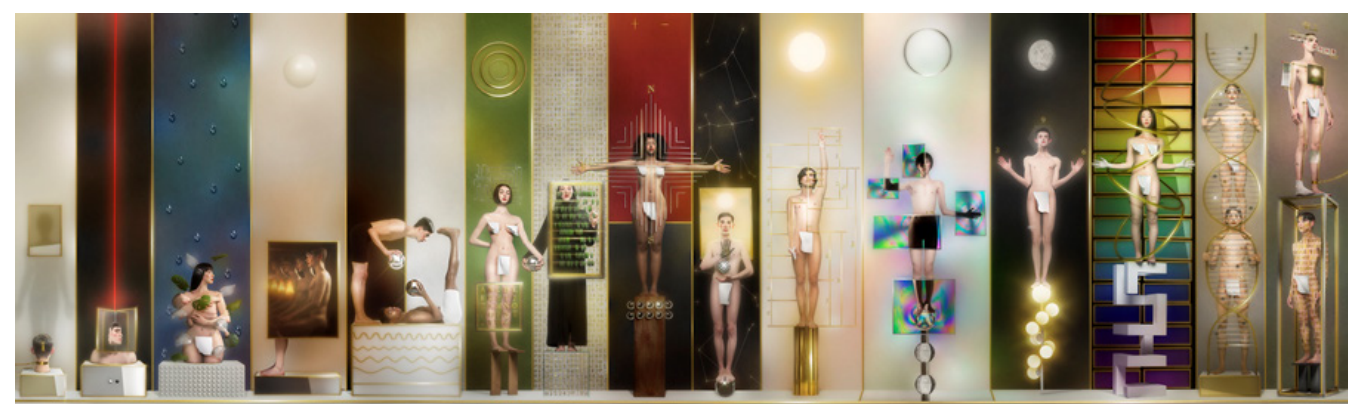

Figura 12. Exposición Homo-? De Filip Custic en La Térmica. https://www.latermicamalaga.com/actividades/exposicion-homo-filip-custic/

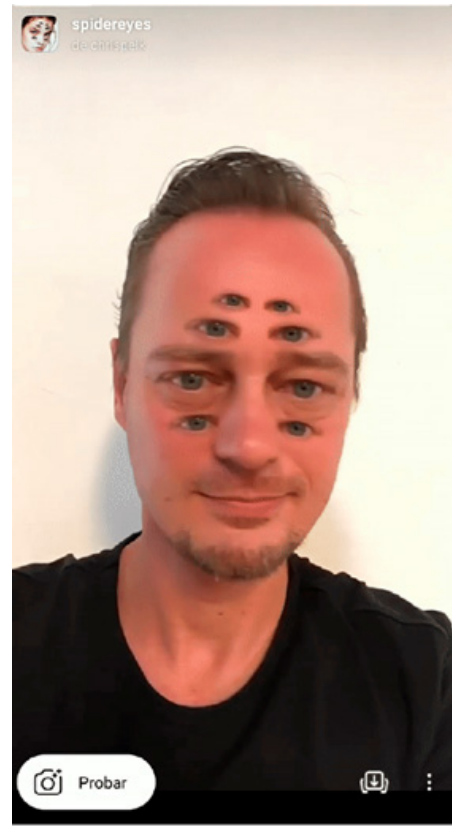

Figura 13. Captura de pantalla del filtro Spider Eyes. Instagram.com/chrispelk

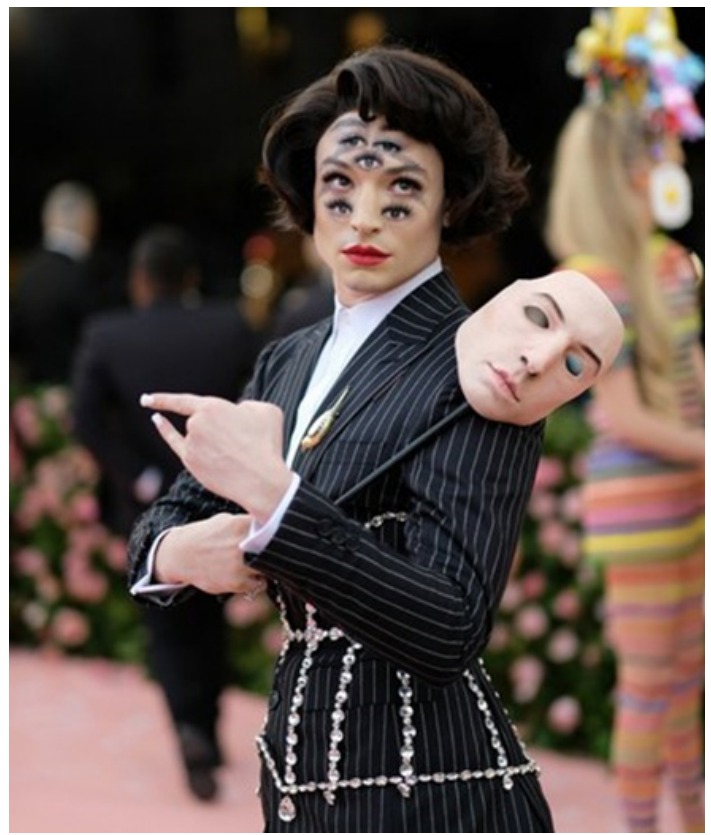

Figura 14. Ezra Miller en la gala del MET 2019. https://www.vogue.es/celebrities/gala-met/articulos/ ezra-miller-gala-met-2019-burberry-maquillaje-ojosmascara/40287 


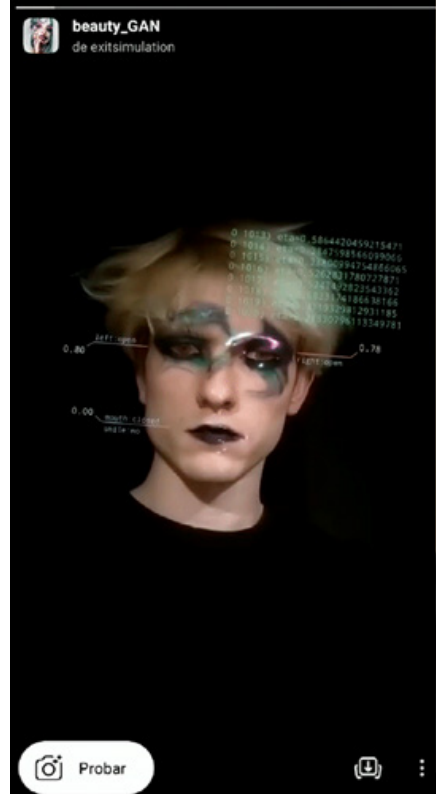

Figura 15. Captura de pantalla del filtro Beauty_GAN. Instagram.com/exitsimulation

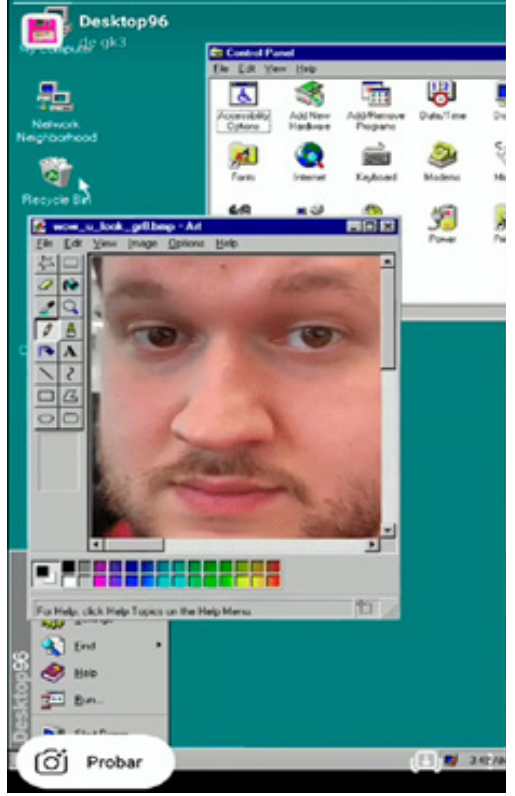

Figura 16. Captura de pantalla del filtro Desktop 96. Instagram.com/gk3

Todos estos imaginarios futuristas conviven, sin embargo, con una corriente estética llamada vaporwave que hace alusión a una clara nostalgia por un pasado en el que las tecnologías no estaban tan desarrolladas. Ante esta corriente podemos aludir al concepto de retromanía que Simon Reynolds (2011) plantea:

This kind of retromania has become a dominant force in our culture, to the point where it feels like we've reached some kind of tipping point. Is nostalgia stopping our culture's ability to surge forward, or are we nostalgic precisely because our culture has stopped moving forward and so we inevitably look back to more momentous and dynamic times? But what happens when we run out of past? (p.14)

Ante esta pregunta que se hace Reynolds podemos contestar, y afirmar, que el pasado siempre vuelve y más con las prácticas de reapropiación y la construcción de identidades que las generaciones de nativxs digitales realizan activamente a través de estos filtros. Lo camp se basa en gran medida en recuperar elementos pasados y presentarlos reinventados mediante la exageración y la parodia, presentándolos como algo futurista. Por lo tanto, recuperando el pasado presentamos el futuro y esto es algo que mediante las redes sociales y los filtros podemos llevar a cabo constantemente. En este sentido, el vaporwave es una estética que evoca una melancolía por un mundo en transición entre lo digital y lo analógico, en el que internet estaba comenzando a desarrollarse y que coincide con el nacimiento de buena parte de la generación millennial. 
Un ejemplo de esta estética es la que propone @gk3, quien ha diseñado el filtro Desktop96 (ver Fig. 16). Un filtro que imita un escritorio de Windows 96, interfaz que buena parte de Ixs usuarixs milennials de Instagram a penas habrán conocido.

Más allá de la estética, el uso de los face filter es un gesto camp: una imagen performativa (en el sentido de teatralidad y mascarada), lúdica, que se encarna en el propio cuerpo permitiendo adoptar una identidad elegida, en un gesto de emancipación. Y ese gesto de elegir, de escoger qué máscara e identidad puedes ser con un click, es en sí mismo un gesto emancipador, que permite la materialización de lo que José Esteban Muñoz llama una utopía concreta (Rosenberg, 2018): utopías que se materializan a partir de prácticas culturales y que sólo existen en espacios materiales frágiles como son los cuerpos y tiempos vertiginosos como las redes sociales.

\section{CONCLUSIONES}

A lo largo del presente artículo hemos podido ofrecer un recorrido por el universo de lo camp. Primeramente, hemos señalado la historia; desde los orígenes del término, su evolución y resignificación después de Stonewall, mostrando las distintas discusiones en torno al término. Seguidamente se ha hecho un recorrido en torno a cómo lo camp está penetrando en las industrias culturales contemporáneas: desde la moda, pasando por la música, el cine y la publicidad. Como hemos podido comprobar, la inclusión de las prácticas camp en las industrias culturales es algo totalmente recurrente y, por lo tanto, efectivo a nivel de identificación con el público. Lo camp se basa en llevar todo aquello que podamos imaginar y soñar al extremo, y proyectarlo como algo mágico, increíble y, por supuesto, no normativo. Jugando con elementos retro, kitsch, recurriendo a la nostalgia y presentando un futuro estéticamente fantástico, lo camp siempre va a estar presente en los productos creados para el ocio y la cultura pop de cualquier generación.

Seguidamente se ha propuesto un análisis sociocultural en torno a cómo lo camp penetra en las generaciones $\mathrm{Y}$ y $\mathrm{Z}$ a través de las redes sociales y nuevos movimientos estéticos y culturales. Generaciones cuya presencia en redes sociales como Instagram es mayoritaria, y cuyo consumo de contenido es activo, conformando un perfil de prosumidxr y produsuarix. Hemos podido comprobar que la fuente del creador de contenido se basa en la apropiación y re-significación propia de las culturas hipertextuales. Esto crea una conversación entre usuarixs e industria que en las redes sociales se vuelve especialmente llamativa, ya que las nuevas estrategias de marketing digital y Ixs influencers hacen que sea difícil distinguir dónde empieza el usuario y dónde acaba la industria. El acento en el contenido del usuario permite un espacio de difusión de imaginarios no normativos que hace posible un consumo cultural y alternativo. El hecho de que la industria haya puesto en la agenda lo camp, ha hecho que las generaciones $Y$ y $Z$ no solo puedan apropiarse de este imaginario, sino que también lo re-interpreten y re-produzcan de acuerdo con las gramáticas visuales del momento. Finalmente, hemos ofrecido un análisis sobre los filtros faciales, entendiéndolos como una "táctica" que Ixs usuarios de Instagram han creado y a través de la cual se difunden y reproducen imaginarios camp.

Hoy, a través de las redes sociales y las posibilidades comunicativas que allí se generan, podemos performar identidades y contar(nos) con la libertad que nos permite la mediación de las pantallas, y la sofisticación de los nuevos recursos virtuales. Desde un punto de vista de la mediología, y tomando Las leyes de los medios de McLuhan (2009) como referente, 
comentaremos lo que consideramos las mayores aportaciones de este nuevo entorno mediático que propone Instagram con respecto a lo camp. El nuevo medio extiende la subcultura camp, conectando usuarios en la red y generando comunidades globales con una sensibilidad común. Además, acelera su propagación gracias al peso visual que prevalece en la plataforma y hace posible su expansión dentro de las nuevas generaciones $Y$ y $Z$, a la vez que reduce el significado histórico, las referencias culturales e históricas debido a la inmediatez del lenguaje visual. Pero este nuevo medio, Instagram, promueve unas acciones de recuperación donde se integran y adaptan las estéticas que históricamente se han relacionado con lo camp y afianzan el sentimiento de comunidad no normativa entre freaks, queer y outsiders. Instagram, como nueva forma mediática, ha potenciado que estas identidades vuelvan a ser una novedad, una tendencia y a causar admiración, revuelo e indignación puesto que lo camp es un fenómeno que despierta en momentos de cambio y ruptura con la cultura hegemónica: es una respuesta a momentos de estancamiento.

Por lo tanto, podemos afirmar que, por un lado, el espíritu de lo camp se haya en el cuestionamiento de lo que se entiende por natural. La sensibilidad camp resurge necesariamente en un momento de cambio global cuyo cometido es recordarnos que "lo normal" no existe. Lo camp (al igual que el meme), está en el ojo de quien lo mira, especialmente si el que lo mira es camp (Core, 1984). Y, por otro, que las redes sociales facilitan el acceso a ese tipo de cuestionamientos, sobre todo en términos generacionales, pues las comunidades que se forman en Instagram y redes similares propician la conexión entre usuarixs con localizaciones diferentes, pero ideas e identidades muy similares, ayudando a que sean capaces de reflexionar sobre si lo que ven, piensan y sienten puede ir a más y no quedarse en lo hegemónico, en lo normativo, y poder proyectarlo al resto del mundo. 


\section{REFERENCIAS}

Adorno, T. y Horkheimer, M. (2007). Dialéctica de la Ilustración. Madrid: Ediciones Akal.

Ahmed, S. (2015). La política cultural de las emociones. México: Universidad Autónoma de México.

Austin, G., Qiong Yu, S. y Malinowska, A. (2017). Heroines at the Outskirts of Culture. Hollywood Stardom in Intra-and Transcultural Practices of Camp. En Sabrina Qiong Yu y Guy Austin (Eds.) Revisiting star studies. Cultures, themes and methods, (pp.187-204). Edinburgh Scholarship Online.

Barrio, A. (6 de mayo de 2019). Filip Custic: No nos damos cuenta de cómo internet nos está domando. El Mundo. Recuperado de www.elmundo.es

Barthes, R. (2009). La aventura semiológica. Barcelona: Paidós.

Benito, C. (1 de octubre de 2019). El filtro de Instagram que ha revolucionado a las famosas. La Razón. Recuperado de www.larazon.es

Bolter, D. y Grusin, R. (2011). Inmediatez, hipermeciación y remediación. CIC. Cuadernos de Información y Comunicación, 16, 29-57.

Bruns, A. (2009). Blogs, Wikipedia, Second Life, and beyond. Nueva York: Peter Lang.

Butler, J. (2004). Lenguaje, poder e identidad. Madrid: Síntesis.

Butler, J. (2007). El género en disputa. El feminismo y la subversión de la identidad. Barcelona: Paidós.

Christian, A. J. (2010). Camp 2.0: A Queer Performance of the Personal. Communication, Culture \& Critique, 3, 352-376.

Curran, J., Morley, D. y Walkerdine, V. (1998). Estudios culturales y comunicación. Análisis, producción y consumo cultural de las políticas de identidad y el posmodernismo. Barcelona: Paidós.

De Certeau, M. (2000). La invención de lo cotidiano 1. Artes de hacer. México: Universidad Iberoamericana.

Furundarena, A. (2 de junio de 2019). Eduardo Casanova, artista: 
"Siento cierta empatía hacia los dictadores". Las Provincias. Recuperado de www.lasprovincias.es

Gómez, B. (15 de marzo de 2019). Palomo Spain: “El camp es necesario". Vogue. Recuperado de www.vogue.es

Halberstam, J. (2008). Masculinidad femenina. Madrid: Egalés

Hueso Fibla, S. (2009). Laberintos teóricos de lo Camp. Actas del II Congreso Internacional "Cuestiones críticas". FHyA-UNR, Rosario, Argentina.

Jauss, H. (1986). Experiencia estética y hermenéutica literaria. Madrid: Alfaguara.

Jiménez, G. (2019). Prácticas fotográficas contemporáneas en la cultura digital: Hacia un giro performativo. CIC. Cuadernos de Información y Comunicación, 24, 175-186.

Lang, C. (2 de mayo de 2019). What Does Camp Mean Exactly? A Comprehensive Guide to the 2019 Met Gala Theme. Time. Recuperado de https://time.com/

Larousse, É. (2019) Larousse.fr : encyclopédie et dictionnaires gratuits en ligne. Recuperado de https://www.larousse.fr/ portail/

Leclerc-Mougne, A. (2019). Pourquoi la mode se passionne pour le Camp. Magazineantidote. Recuperado de www.magazineantidote.com

Macdonald, F. (27 de Julio de 2017). The secret language that broke taboos. BBC. Recuperado de www.bbc.com

Marinas, L. (2019). Instagram: Donde Millennials, Generación Z, Mcluhan y Bolter se cruzan. CIC. Cuadernos de Información y Comunicación. 24, 187-201.

Martín Prada, J. (2017). Sobre el arte post-internet. Aureus, 3, 45-51.

McLuhan, M. y McLuhan, E. (2009). Las leyes de los medios. CIC. Cuadernos de Información y Comunicación, 14, 285-316.

Newton, E. (2016). Mother Camp. Un estudio de los transformistas en los Estados Unidos. Barcelona: Múltiplos books. 
Platero, R. L, Rosón, M. y Ortega, E. (2017). Barbarismos queer y otras esdrújulas. Barcelona: Bellaterra.

Reynolds, S. (2011). Retromania: Pop Culture's Addiction to its Own Past. Nueva York: Faber And Faber Ltd.

Rosenberg, S. y Sharp, M. (2018). Documenting queer(ed) punk histories: Instagram, archives and ephemerality. Queer Studies in Media and Popular Culture, 3(2), 159-74.

Shifman, L. (2014). Memes in digital culture. Massachusetts: MIT Press.

Simón, A. (16 de mayo de 2019). Retratando la marginalidad entre sábanas de satén. Vice. Recuperado de www.vice.com

Sontag, S. (2018). Contra la interpretación y otros ensayos.

Barcelona: Debolsillo.

Suárez Villegas, J. C. y Cruz Álvarez, J. (2015). Cambios en los patrones de consumo entre los estudiantes de periodismo: de prosumidores mediáticos a profesionales de la información. Estudios sobre el Mensaje Periodístico. 21(1), 615-628.

Toffler, A. (1991). The Third Wave. Nueva York: Bantam Books.

Wilde, O. (2012). Intenciones: La decadencia de la mentira; Pluma, pincel y veneno; El crítico como artista; La verdad de las máscaras. Madrid: Valdemar.

Williams, R. (1977). Estructuras del sentir. En Marxismo y literatura. (pp.150-158). Barcelona: Ediciones Península. 
1. Definición consultada en https://www.larousse.fr/dictionnaires/francais/se_ camper/12561

2. “Aunque Wilde no usó la palabra camp, uno de sus epigramas más famosos de la obra An Ideal Husband (1895) ha llegado a encarnar las raíces victorianas de la sensibilidad: "Ser natural es una pose muy difícil de mantener". Ser natural se define aquí como una pose en sí misma y, por lo tanto, pierde su significado más obvio al estar conectado, en cambio, con la estética con la que lo camp también está vinculado." (Prono, 2008, p.53)

3. “La conexión de camp con Hollywood se ha manifestado de dos maneras: a través del trabajo de artistas queer dentro de la industria del entretenimiento convencional, y a través de las relecturas trans-semióticas de las narrativas de Hollywood, específicamente las imágenes de estrellas, con las que el público queer se ha comprometido con el propósito de alterar la percepción social de lo extraño." (Austin, Qiong Yu y Malinowska, 2017, p.190)

4. “(Camp) se vuelve cada vez más dominante en su pluralidad: camp político, camp queer, camp pop, la fusión de lo alto y lo bajo, la idea de que no existe la originalidad." (Bowles, 2019)

5. "Estamos atravesando un momento camp extremo, y se siente muy relevante para la conversación cultural mirar lo que a menudo se descarta como una frivolidad vacía, pero que en realidad puede ser una herramienta política muy sofisticada y poderosa, especialmente para las culturas marginadas." (Friedman, 2018)

6. “Lo camp no solo es aplicable a las expresiones artísticas hechas por homosexuales para el consumo de una audiencia queer, sino que se extiende a los textos principales cuyas imágenes, ideologías y lecturas los califican como de heterosexualidad." (Prono, 2008, p.52)

7. “Lo camp se basa mucho en esta actitud irónica hacia el kitsch, al igual que las formas "posmodernas" de usar motivos kitsch que intentan desafiar los estándares estéticos oficiales." (Botz-Bornstein, 2019, p.90)

8. "Estos artistas han rehecho lo camp para un mundo postqueer y de nuevos medios." (Christian, 2010, p.370)

9. "La pantalla y el ordenador crean múltiples identidades, creando una experiencia fragmentada." (Christian, 2010, p.354).

10. "Sin embargo, lo camp online es demasiado personal y singularmente importante para muchos artistas jóvenes separarlo. Esta división generacional entre los artistas camp más tradicionales y los más jóvenes, con mentalidad Web 2.0 que están personalmente más interesados tiene sus raíces en la historia." (Christian, 2010, p.369)

11. "Los videos de Youtube (...) sugirieron un cambio históricamente específico en la relación de los jóvenes con los nuevos medios, lo camp y la historia queer, marcando el paso del 
camp marginal, irónico y formador de comunidad a formas online más mainstream, serias e inflexionadas personalmente." (Christian, 2010, p.357)

12. "Si bien los memes son artefactos aparentemente triviales y mundanos, en realidad reflejan profundas estructuras sociales y culturales." (Shifman, 2014, p.15)

13. "Responde a la fabricación del mago y a la producción del deseo, atribuido a la creación de fantasía de pantalla y, como tal, se convierte en una plataforma para prácticas que explotan ambas "actuaciones en pantalla" y los "significados sobre la identidad humana" que representan." (Austin y Malinowska, 2017, p.188) 